\title{
RAPSODIA PARA UNA REVUELTA SOCIAL: RETAZOS NARRATIVOS Y EXPRESIONES GENERACIONALES DEL 18-O EN EL CHILE ACTUAL
}

\author{
Rhapsody of a Social Outbreak: \\ narrative snippets and generational expressions of $18-W$ in present- \\ day Chile
}

\section{RESUMEN}

El presente artículo forma parte de la reflexión teórica sustentada en la evidencia acumulada por más de 20 años de trayectoria e investigación en el campo de los Estudios de Juventudes en el Chile reciente. El objetivo básico del artículo es presentar el trabajo preliminar de contextualización del estallido social 18-O, la discusión bibliográfica y las hipótesis de trabajo provisorias, poniendo en perspectiva lo ocurrido en el marco del denominado estallido social en Chile, particularmente desde lo que llamamos las implicancias generacionales puestas en juego en este acontecimiento. La metodología responde a lo que se conoce en ciencias sociales como Multimétodo, lo que incluye una variedad de técnicas para levantar datos que van desde la aplicación de entrevistas en profundidad, observación participante, revisión de prensa y análisis crítico de literatura. Los principales resultados de esta discusión teórica que aquí presentamos, plantean un fenómeno de repolitización de la política que se viene fraguando de modo paulatino y progresivo en Chile, particularmente visible desde inicios del siglo XXI. Sumado a lo anterior, se postula la emergencia de una nueva subjetividad política de carácter generacional para el actual escenario social y político.

\footnotetext{
Palabras claves: Revuelta Social, Malestar Social, Subjetividad Política, Repolitización, Generaciones.
}

UNIVERSUM

Revista de Humanidades y Ciencias Sociales

\section{RODRIGO GANTER SOLÍS}

Sociólogo, Doctor en Estudios Urbanos, Universidad Católica de Chile. Docente e investigador del Departamento de Sociología de la Universidad de Concepción, Chile. Coordinador Grupo de Trabajo Juventudes, Red Iberoamericana de Investigación en Imaginarios y Representaciones.

Correo electrónico: rganter@udec.cl

ORCID: 0000-0002-3683-2357 ResearchGate: Rodrigo_Ganter Scholar.google:

Academia.edu: GanterR

\section{RAÚL ZARZURI CORTÉS}

Sociólogo, Magister en Antropología y Desarrollo, Universidad de Chile. Doctor (C) en Educación, Universidad Academia de Humanismo Cristiano - Chile. Docente e investigador de la Escuela de Sociología, Universidad Académica de Humanismo Cristiano, Chile.

Correo electrónico: rzarzuri@gmail.com

ORCID: 0000-0001-6653-5794 ResearchGate: Raul_Cortes 15 Scholar.google:

Academia.edu: raúlzarzuri

Artículo recibido el 31 de marzo, 2020. Aceptado el 7 de juLio, 2020.

DOI:

Web: http://universum.utalca.cl | ISSN: 0716-498X - 0718-2376 


\section{ABSTRACT}

This article is part of the theoretical reflection supported by the evidence accumulated by more than 20 years of experience and research in the field of Youth Studies in recent Chile. The basic objective of the article is to present the preliminary work of contextualization of the $18-\mathrm{O}$ social outbreak, the bibliographic discussion and the provisional working hypotheses, putting into perspective what happened in the framework of the so-called social outbreak in Chile, particularly from what we call the Generational implications put into play in this event. The methodology responds to what is known in the social sciences as Multimethod, which includes a variety of techniques to collect data ranging from the application of in-depth interviews, participant observation, press review, and critical analysis of literature. The main results of this theoretical discussion that we present here raise a phenomenon of political re-politicization that has been gradually and progressively forging in Chile, particularly visible since the beginning of the $21 \mathrm{st}$ century. In addition to the above, the emergence of a new generational political subjectivity for the current social and political scenario is postulated.

Keywords: Social Outbreak, Social Unrest, Political Subjectivity, Repolitization, Generations.
Este artículo constituye parte de la reflexión y la difusión de resultados provisorios al interior de dos proyectos de investigación de los cuales los autores son coordinadores en ambas iniciativas: Proyecto "Repertorios de acción colectiva en los ciclos de protestas del año 2018 y 2019 en el Gran Concepción"; financiado por Vicerrectoría de Investigación y Desarrollo de la Universidad de Concepción (Vrid ${ }^{\circ}$ 2019.209 / 2020-2021); y "Sujetos del Levantamiento en Chile, 18-O 2019", financiado por la Fundación Rosa Luxemburgo (2020). 


\section{INTRODUCCIÓN}

Lo que aquí presentamos forma parte de la discusión teórica y la reflexión colectiva sustentada en la evidencia acumulada por más de 20 años de trayectoria e investigación en el campo de los Estudios de Juventudes en el Chile reciente. Sumado a lo anterior, el conjunto de hipótesis de trabajo que aquí presentamos forma parte de 2 proyectos de investigación vinculados con la problematización del estallido social del 18-O desde la perspectiva generacional. El primero de ellos se inscribe en un fondo financiado por la Fundación Rosa Luxemburgo (2020), sobre sujetos del levantamiento 18-O en Chile; y el segundo proyecto está financiado por la Vicerrectoría de Investigación y Desarrollo de la Universidad de Concepción, Chile (2020); cuyo objetivo se encuentra asociado con la comprensión de los Repertorios de Acción Colectiva en los Ciclos de Protestas de los años 2018 y 2019 en las ciudades de Santiago y Concepción. La metodología responde a lo que se conoce en ciencias sociales como Multimétodo, lo que incluye una variedad de técnicas para levantar datos que van desde la aplicación de cuestionarios y entrevistas en profundidad, hasta observación participante y análisis de prensa. El propósito básico es presentar el trabajo preliminar de contextualización del estallido social 18-O, la discusión bibliográfica y las hipótesis de trabajo provisorias en las cuales convergen ambos estudios, poniendo en perspectiva lo ocurrido en el marco del denominado estallido social en Chile, particularmente desde lo que llamamos las implicancias generacionales puestas en juego en este acontecimiento. Los principales resultados plantean un fenómeno de repolitización de la política que se viene fraguando de modo paulatino y progresivo en Chile, particularmente visible desde inicios del siglo XXI. Sumado a lo anterior, se postula la emergencia de una nueva subjetividad política de carácter generacional. 


\section{CONTEXTOS Y ESCENARIOS}

A partir de la coyuntura definida por el movimiento estudiantil del año 2006 y el año 2011 en Chile, se viene experimentando un incremento exponencial de las movilizaciones sociales y expresiones de protesta colectiva. A partir de esa evidencia, el Programa de Naciones Unidad para el Desarrollo Humano (PNUD-Chile, 2012) inicia una reflexión en torno a dicho tópico, intentando generar respuestas a preguntas como: ¿qué explica las movilizaciones sociales masivas en un contexto de crecimiento económico? ¿de dónde surge el malestar social que experimenta la sociedad chilena? Más paradojal aún, en un escenario donde Chile se ubica en el primer lugar de América Latina y el Caribe en Desarrollo Humano (PNUD, 2012). En ese plano, se advierte la estructura de una insatisfacción o un malestar social determinado por el modelo de sociedad configurado en los últimos treinta años. En la mayoría de ellos aparece como telón de fondo el fenómeno de la desigualdad. Hay que señalar que a fines de los noventa el malestar social en Chile era difuso, contenido y no se expresaba socialmente, mientras que ahora es explícito, activo y se expresa de modo colectivo y transversal, esto se aprecia en el notable incremento de las protestas y movilizaciones sociales (PNUD, 2012/2015).

Otras expresiones de este malestar social se manifiestan en la evaluación/percepción negativa y crítica de la ciudadanía hacia su sociedad. Los indicadores son múltiples, ya sea en relación con las instituciones sociales, el sistema político, el modelo económico, las interacciones cotidianas, entre otras cosas. Se observa críticamente la desigualdad social, la concentración del poder, la representatividad de las instituciones, la discriminación, el abuso y desconfianza predominantes en las relaciones sociales. En síntesis, los chilenos en su gran mayoría no confían en las instituciones de la sociedad (PNUD, 2012, 2015). Esta corriente y percepción de carácter ubicuo se hace mucho más radical y evidente en las nuevas generaciones. 
Asimismo, la irrupción explosiva de ese malestar social, bajo la inédita forma de protesta multiforme o revuelta social extendida durante el denominado estallido social, no es una cuestión que no haya sido advertida. Ya había signos importantes de un malestar ubicuo, no solo frente a las cuestiones asociadas con el extremismo en la aplicación del modelo neoliberal y las cuestiones de abuso, el sobreendeudamiento de las familias, el agobio interpersonal, la precariedad y el ensimismamiento por parte de las elites económicas y políticas, sino con el ethos cultural que sustenta esas estructuras, esto es, una forma naturalizada de construir el lazo social mediante la cual todo malestar y fragilidad humana es resuelta a través de la gestión de agentes privados y/o expertos, esto es, mediante la racionalidad técnica y mercantil, o bien, apelando a las competencias personales, la resiliencia individual y el empresariado de sí. Sin embargo, por más que se haya secuestrado o puesto limites importantes en treinta años al poder ciudadano de incidir de modo activo y participativo en los asuntos públicos, y a pesar del mantra de que la "sociedad no existe", esta no solo dio pruebas de su existencia en una versión generacional, sino que mostró su lado más oscuro y disruptivo, acumulado por un ciclo largo de descontentos latentes.

\begin{abstract}
Así, la aspiración por una mayor incidencia ciudadana en el control de los principales recursos para la producción y reproducción de la vida social es una aspiración de escala global y de demanda localizada. Sostenemos que estos "enjambres de malestar ciudadano" no son meramente reactivos a los acontecimientos o a las crisis sistémicas, sino que constituyen sedimentos socio-afectivos y de memoria social crítica que en algún momento - como el magma de un volcán— estallan y se funden las antiguas rabias y aspiraciones populares con la actualización del descontento social, potenciado esto último por la viralización operada por las nuevas tecnologías de la información y la comunicación del momento actual, y cuyo uso no se agota en el simple y puro consumo, sino que deviene en creación de vínculos de nuevo tipo y redes socio-afectivas que promueven la desestabilización de las estructuras sociales que nos rigen (Ganter y Vergara, 2015: 166)
\end{abstract}

Por su parte, las elites miran con resquemor las nuevas dinámicas sociales advirtiendo en ellas la posibilidad de un escenario de demandas sin control. La ciudadanía desconfía de todos los actores que tienen poder en los distintos ámbitos de la vida social. Los desafíos que implica el proceso de 
"politización" en curso requerirá encontrar los mecanismos para superar esta situación de desconfianza mutua que entraba las posibilidades de acción del conjunto de la sociedad (PNUD, 2015).

Pero ¿cómo se puede entender este tipo de rebeliones, que no solo se han manifestado en nuestro país? Si se analiza el informe sobre Protesta Social en América Latina (2012) realizado por el Programa de las Naciones Unidas para el Desarrollo, se observa que en los países más desiguales y con altos índices de desconfianza interpersonal y en las instituciones (como el caso chileno), hay una mayor propensión a que se desaten acontecimientos como los iniciados el 18-O, con episodios que involucran protestas masivas y violencias de diverso origen. El informe "World Protests 2006-2013" (Ortiz et al. 2013), realizado en 84 países, muestra como a partir del año 2010 las protestas se intensifican, identificando cuatro grupos de causas: justicia económica (488 episodios); crisis políticas y del modelo de democracia (376); resistencia frente a organismos internacionales o tratados de libre comercio (311); defensa de los derechos humanos y a los bienes comunes (302).

El caso chileno no constituye una excepción en el contexto global y latinoamericano. Lo que sí es importante reconocer, a manera de distinción, es que las cuatro causas que señala el World Protests se presentan de modo simultáneo y sincrónico durante el año 2019 y se influyen mutuamente. Más allá de esta explosión sincrónica de octubre, el primer semestre del año 2019, con el llamado Tratado Integral y Progresista de Asociación Transpacífico (TPP11), se habían experimentado, particularmente en escenarios universitarios, señales de esa energía "volcánica" que se venía acumulando por más de 30 años. Lo propio ocurría con el movimiento de resistencia del pueblo Mapuche y los ciclos de protesta ligados a las movilizaciones estudiantiles que parten con el mochilazo (2001), la revuelta pingüina (2006); el movimiento estudiantil de 2011; y el mayo feminista chileno de 2018 . $^{1}$

Por último, habría que señalar que en general, a partir del año 1988 y

1 Parafraseando a P. Güel (2019), el relativo silencio o negación recurrente de muchos centros de investigación chilenos (think thank) para anticiparse parcialmente al estallido social, a pesar de su investigación sistemática por casi una década, indica que parte importante de la investigación sobre 
luego de modo más evidente a fines de los años 90, N. Lechner y el PNUD (1998), quienes venían indagando acerca de la dimensión subjetiva de la política, muestran una profunda inquietud y preocupación por el problema del malestar en la sociedad chilena. Este fenómeno, pasa de ser un magma silencioso y de perfiles fragmentarios, muchas veces subsumido, sublimado y naturalizado por la sociedad chilena, a tener un carácter colectivo, extendido y transversal, cuestión que también lo testeó con fuerza el PNUD el año 2012 y 2015, pero esta vez con una carácter más radical y multiforme, asociado con temas de abuso, agobio, desigualdad, precarización, desconfianza en las instituciones, ensimismamiento de las elites, etc.

\section{INTERPRETANDO LA REVUELTA SOCIAL 18-O}

Una de las primeras cuestiones que se debe señalar respecto del $18-\mathrm{O}$ es que las movilizaciones actuales muestran que estamos en presencia de una transformación de la acción política, la cual se caracteriza por su forma inorgánica y transversal. No responde a la lógica de izquierdas y derechas, sino más bien al eje vertical donde se ubica, por un lado, la élite, y por otro, los de abajo. Tampoco responden a la dinámica de un movimiento social clásico, con la conducción de líderes. No predominan las ideologías, sino las causas de diversa procedencia, lo que se conoce como activismo sincrónico y acción conectiva generacional (Reguillo, 2017); donde lo importante no es tanto quién emite el mensaje, sino quiénes lo reciben y qué hacen con ese mensaje (como en el caso del colectivo LASTESIS). De ahí la proliferación de redes con escasa estructura, las comunidades autoconvocadas, las asambleas barriales, los cabildos ciudadanos, las coordinadoras como 8M, No + AFP, Modatima, Ukamau, el colectivo LASTESIS, etc. sin relación directa con actores políticos convencionales. Al final del día, no hay un actor que represente demandas, ni peticiones definidas y jerarquizadas con claridad, por lo cual se

conflictividad social en Chile está en deuda con el debate público, y por tanto sus esquemas, métodos e incentivos de producción de conocimiento deben ser reconsiderados con urgencia, dado el relativo fracaso en sus objetivos prioritarios de mediano y largo plazo. 
hace más complejo procesar institucionalmente el clamor "coral" de la calle y la multitud. Por último, habría que revelar "la ocupación permanente del espacio público como una reivindicación de la autonomía y la recuperación de espacios propios o las acciones carnavalescas de reminiscencias (neo)tribales" (Zarzuri, 2020: 6).

En cuanto a los factores detonantes más relevantes para la participación en las protestas destacan, en nuestras recientes indagaciones, ${ }^{2}$ para el componente juvenil: (a) el efecto imitación y/o contagio de pares (muchas veces promovida por redes sociales); (b) la sensación crónica de frustración, exclusión y abuso de poder; (c) la desconfianza y la indignación derivada de la brutalidad con la que ha actuado Carabineros en el contexto del estallido social; (d) la necesidad de protección y resguardo organizado, por parte de la denominada "primera línea", de las marchas y los propios manifestantes más vulnerables.

De este modo, bajo el estallido social y el levantamiento ciudadano del 18-O hay la expresión y convergencia compleja de múltiples malestares colectivos que la sociedad chilena arrastra y viene acumulando al menos por tres décadas, lo cual ha permitido que brote lo que podemos denominar como "máquina de lucha", que se alzó para lidiar contra la indiferencia frente a la situación de desmedro económico, social y cultural que viven vastos sectores de nuestro país, y que ha permitido, que otros, que no tienen problemas en la producción de la vida cotidiana, se hayan sumado. En ella, "convergen una multiplicidad de deseos y afectos que se unen, y lo más interesante, sin que se suprima lo diverso o lo heterogéneo de los intereses de quienes concurren a las manifestaciones". (Zarzuri, 2020: 2).

Hay que señalar también, que el 18-O no obedece a algo coyuntural, sino que nos enfrentamos a una ola o ciclo de protesta que, a diferencia de otras movilizaciones, no se ha focalizado en arremeter sobre una parte del sistema, sino que la protesta es contra la totalidad del sistema, o sea, se asiste a una demanda por construir una

2 Proyecto financiado por la Vrid, Universidad de Concepción, sobre Repertorios de Acción Colectiva en los Ciclos de Protestas de los años 2018 y 2019 en el Gran Concepción 2020-2021. 
sociedad distinta, donde la vida cotidiana se vea resguardada. Asistimos entonces, a la emergencia de un tipo de acción colectiva que es desarrollada por personas que no tienen acceso a las instituciones y que levantan reivindicaciones que no han sido aceptadas por el sistema, convirtiéndose en una amenaza. Esto, desde la teoría de Sidney Tarrow (1997) pueden conceptualizarse como una forma de "política contenciosa transgresiva", donde los actores y las formas de levantar demandas no estaban institucionalizados.

\section{JÓVENES, DERECHOS HUMANOS Y CRIMINALIZACIÓN DURANTE EL 18-O}

En el marco de la contextualización sobre el 18-O surge una pregunta: ¿Qué papel juegan los/las jóvenes en todo esto? En perspectiva histórica, sostenemos que han sido de preferencia actores generacionales, particularmente jóvenes adscritos a la educación secundaria y universitaria, los que se han manifestado e impugnado mediante acción directa y tácticas de acción colectiva callejera, de fuerte factura e impacto simbólico-comunicacional (Ganter, 2017); los que han dotado de organicidad al malestar, demandando no solo medidas correctivas al modelo, en este caso educacional/económico, sino también cambios estructurales en el sistema político, la economía, la gestión de la vida y los bienes comunes, entre otros.

En relación con el perfil de los más afectados por la violencia directa en este contexto de protestas sociales masivas, extendidas y sostenidas en el tiempo, incluye una gama muy amplia de víctimas, que considera desde pérdidas de vidas humanas hasta alteraciones en la salud mental de la población. Las estadísticas del informe de Human Rights Watch para Chile $2019,{ }^{3}$ muestran que desde el 18 -O hasta el 22 de noviembre, existen 11.564 casos de personas heridas en manifestaciones, de preferencia los más afectados pertenecen al segmento joven. En diciembre el INDH presentó querellas por 617 casos de torturas y tratos crueles. ${ }^{4}$ En ese mismo sentido, el reporte de la Sociedad Chilena de Oftalmología $^{5}(21 / 11 / 19)$ señala la existencia de 220

3 https://bit.ly/2PgMBne

$4 \mathrm{https}: / /$ bit.ly/33fw3Ei

5 https://bit.ly/2Xi97Aq 
personas afectadas por traumas oculares, donde el $77 \%$ tiene su origen en impacto por perdigones disparados por Carabineros, concluyendo que se trata mayoritariamente de jóvenes entre los 14 y los 28 años, de los cuales el $87 \%$ son varones y el $13 \%$ mujeres. Según el INDH, esa cifra subió durante el mes de diciembre a 334 personas con traumas oculares y 23 con pérdida ocular. Eso indica prácticas punitivas selectivas muy cercanas a lo ocurrido recientemente en países como Colombia o México a partir de conflictos armados y crisis social, lo que se califica como juvenicidio o intentos de juvenicidio (Valenzuela, 2015). Aquí, frente a la masividad de las protestas, el "tratamiento" para gestionar el orden público que impuso el Gobierno chileno fue peor que el descontento de base, y existe consenso en los analistas que esta situación pasó de ser un efecto del estallido social a configurarse en un combustionante de la furia y el rechazo ciudadano hacia la policía y el Gobierno.
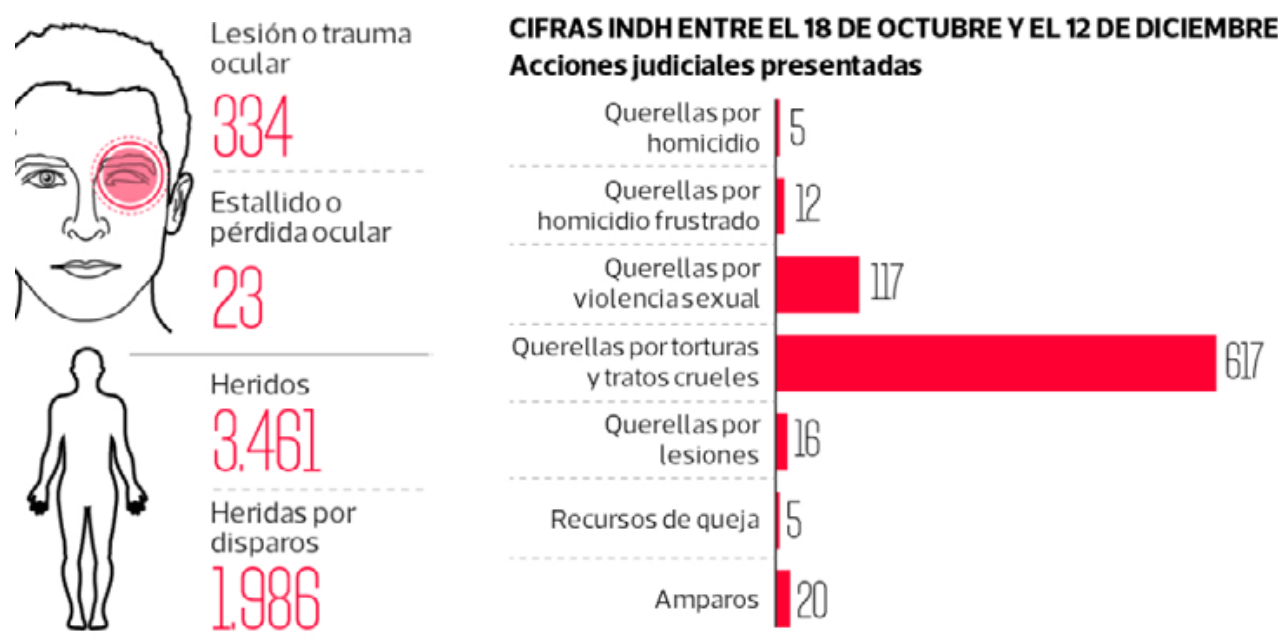

\section{INFOGRAFÍA DIARIO LA TERCERA, 18/12/2019}

Según el Informe de Derechos Humanos de Naciones Unidas para el 18-O en Chile 2019, el mayor costo social y humano de la brutalidad policial y la violación grave a los derechos humanos en escenarios de protesta afectó especialmente a adolescentes y jóvenes. Se suma a esto la criminalización 
mediática de parte de autoridades políticas hacia los jóvenes en el contexto del estallido social.

Uno de los ejemplos más paradigmático de la criminalización en las movilizaciones de octubre por parte del gobierno, medios de comunicación y las instituciones policiales, es lo que ha ocurrido con la denominada "primera línea", transformada en un estereotipo y dispositivo icónico en el cual se plasman de manera controversial para algunos, lo que han sido las movilizaciones del 18O: "En los medios de comunicación los llaman vándalos, vagos, delincuentes. Adentro de la marcha les aplauden, los vitorean, casi los alzan en hombros." (Muñoz, 2019). Se enfrentan a las fuerzas policiales con sus escudos/artefactos fabricados de una diversidad de materiales, reminiscencia de los escudos utilizados en la Grecia antigua, particularmente espartanos y troyanos, los cuales visten de un collage de frases, símbolos e imágenes combinando los mundos del comic con la vida cotidiana. (Zarzuri y Henríquez, 2020). Como señala Claude: "Los escudos están fabricados de forma artesanal con antenas satelitales, barriles, tablas, señaléticas o techumbres y están personalizados con frases o símbolos que los representan." (2020: 5).

Han sido tildados por el gobierno, la clase política y la ultraderecha de: "delincuentes", "vándalos", "lumpen", "antisociales", "violentistas", "Anarcos", "marginales" (Andonie, 2020), sujetos que se pueden ubicar en una categoría asociada al "anarquismo": "Sin Dios ni Ley". Al inicio de las movilizaciones el propio ex Director del Metro de Santiago, Clemente Pérez, twiteaba: "Cabros esto no prendió". El Subsecretario del Ministerio del Interior, Rodrigo Ubilla, señalaba que "esta es delincuencia pura y dura", lo cual era refrendado por la vocera del gobierno de ese entonces, Cecilia Pérez: "esta es una horda de delincuentes". El propio Presidente Piñera señalaba: "Se desató una ola de violencia sistemática, profesional, organizada con tecnología de punta que buscaba destruirlo todo. Querían incendiar el país". ${ }^{6}$

Sin embargo, para otros, son el ejemplo de altruismo, de preocupación por los otros/as, que les ha valido reconocimiento "como sujetos comprometidos

6 https://bit.ly/3hSYhc0 
y valientes que arriesgan su integridad física para defender de la violencia policial al resto de las personas que se manifiestan en el espacio público" . (Fernández, 2019: 1). No menor, señala el mismo autor, ha sido la posibilidad de visibilidad social, de tener una voz, para quienes no la han tenido:

Para muchas y muchos de los participantes de la Primera Línea, este espacio se ha constituido en un espacio de reconocimiento y valoración social que nunca habían tenido, dándole voz y visibilidad a personas que nunca han tenido espacio en los medios de comunicación y de participación política. (2019: 3).

Esto supone hacer un uso de la violencia como una forma de lograr visibilidad de parte de ciertos sujetos, pero también de mostrar problemáticas sociales que de otra manera no serían consideradas.

\section{DEL DESCRÉDITO POR LA CONDICIÓN GENERACIONAL A SU ROL DE AGENTE DETONANTE Y DIFUSOR DE LAS DEMANDAS SOCIALES Y POLÍTICAS EN EL MARCO DEL 18-O}

Partamos aclarando que la noción de generación se desarrolló en Europa a partir de tres momentos históricos que corresponden a tres marcos sociopolíticos concretos: los años 20 , en el período de entreguerras; durante los años 60, la edad de la protesta y el conflicto generacional; fines de los años $90 \mathrm{y}$ el ingreso al siglo XXI, con la aparición de la sociedad red, situación en la que las nuevas generaciones (@; \#) poseen más competencias que las generaciones anteriores para innovar digitalmente (Leccardi et al., 2011; Mannheim, 1993). Para el caso chileno, después de la segunda mitad del siglo XX, aparecen con fuerza distintiva tres generaciones: la del 60; la del 80; y las sucesivas mareas estudiantiles generadas a partir del siglo XXI (Álvarez, 2018; Ghiardo, 2004; González, 2011/2013; Muñoz, 2011; Santibáñez y Ganter, 2016), con sus respectivas "superposiciones" y "enlaces generacionales" impulsados durante los años 2006, 2011 y el 2018, en este último año, en su versión feminista autoconvocada. A lo anterior habría que sumarle el rol que han desplegado las nuevas generaciones en el contexto del denominado estallido social del 18-O. A diferencia de las generaciones ancladas en el siglo XX, la generación actual 
se define por factores cosmopolitas (Leccardi y Feixa, 2011). Siguiendo a Mannheim (1993), planteamos que las generaciones constituyen dimensiones analíticas útiles para el estudio del cambio social, las identidades colectivas, las mentalidades, las emociones y las actitudes que irrumpen y predominan en una época dada.

Por otra parte, observamos que, a pesar de haber dado el puntapié inicial a las movilizaciones sociales, la participación de las nuevas generaciones en el marco de lo que se conoce como "Chile despertó" no ha estado exenta de discusión y de descalificaciones, particularmente en el caso de las organizaciones de estudiantes secundarios (como la Aces o la Cones) y de la llamada "primera línea". Para algunos reputados cientistas sociales chilenos, como por ejemplo Carlos Peña, Mario Waissbluth y Marta Lagos, lo que se ha visto en estas movilizaciones es una forma de protesta que se escapa a cualquier orden normativo, por lo tanto puede ser caracterizada utilizando un viejo concepto sociológico: la anomia. Así, esa falta de normas que se manifiestan en el estallido ha sido utilizada por estos autores para dar cuenta de ciertas prácticas de "violencia juvenil" en el marco de las protestas, particularmente en espacios públicos de algunas ciudades de nuestro país.

Tal como lo hemos planteado en diversas columnas difundidas por la prensa nacional y regional, el concepto de anomia, cuyo origen se remonta e inscribe al año 1897, en pleno auge de las sociedades industriales europeas; y que pensábamos estaba desterrado del análisis social chileno, se utilizó profusamente durante la época de la dictadura cívico-militar para dar cuenta de la participación de un actor que había irrumpido durante las explosivas protestas nacionales de esa época. Nos referimos a la "juventud urbano popular". La interpretación que realizaron algunos connotados sociólogos de la época, mostraba el accionar juvenil como anómico, al destacar solo la emergencia de los deseos y las pasiones: vivir el inmediatismo a través de la evasión o la agresión y simultáneamente vivir el inconformismo. Según estos análisis, no había política en ese quehacer. ${ }^{7}$

7 Revisar columna: https://bit.ly/3fh7BoF 
Ahora, después de cinco meses del estallido social, y observando con mayor distancia y menor afectación emocional los fenómenos asociados con el estallido social del 18-O, particularmente los referidos a episodios protagonizados por las nuevas generaciones, partimos preguntándonos, a parir de las reacciones muchas veces destempladas y reduccionistas de ciertos columnistas: ¿en qué medida la participación de jóvenes en estos eventos se explica porque están siendo "presas de sus pulsiones"? ¿en qué medida estos grupos de jóvenes estarían siendo cautivos de una "falta de orientación normativa de sus propios impulsos"? ¿hasta qué punto se trataría de "un espasmo violento" que no ha logrado expresar una agenda de reivindicaciones coherentes, por lo cual estaríamos frente a una "anomia generacional"?

En Durhkeim, la anomia aparece cuando se estructura una crisis en los marcos normativos de la acción a nivel societal y donde las instituciones tradicionales que entregaban sentido ya no lo estarían otorgando. O sea, las reglas, normas que servían para interpretar el mundo, organizar la vida social y dar cohesión al cuerpo social, se encuentran en entredicho. En un sentido constructivo, la anomia podría leerse como una etapa de tránsito hacia otras formas sociales, que van a reconfigurar - y quizás revolucionariamente-a las sociedades, dotándolas de otras reglas y nuevas formas de cohesión social. El punto es que no es posible adjudicar y endosar una parte importante de la responsabilidad del estallido social y los evidentes desajustes normativos que se vienen arrastrando por más de 30 años en la sociedad chilena, a las nuevas generaciones. Esto es confundir de manera grave y poco seria, además con publicidad y difusión en los medios masivos, el síntoma con la génesis de la crisis social. La mayoría de las veces un buen tratamiento depende sustantivamente de un diagnóstico correcto, y ese no ha sido el caso asociado con estos ilustres columnistas.

Resulta complejo y hasta grave demandar coherencia de modo unilateral y hacerse responsable por nuestras acciones como adultos frente a las nuevas generaciones, cuando en rigor el mudo adulto y las autoridades muchas veces no han estado a la altura, no han actuado precisamente de modo ético y ejemplar durante muchos años, encarnando situaciones anómicas, 
desintegradoras y disruptivas evidentes desde hace varias décadas.

Ejemplo de ello son los abusos al interior de la Iglesia Católica; los montajes y las estafas de Carabineros; los desfalcos en el Ejercito; el financiamiento ilegal de la política, su farandulización y frivolización; la crisis climática y ambiental; el lucro en la educación; el abandono y abuso sistemático al interior del Sename; la colusión de las farmacias y de un sector del empresariado; la segregación socio-residencial y la obscena concentración del ingreso; las evasiones tributarias de altas autoridades de gobierno, la impunidad de las elites; las recientes violaciones graves a los derechos humanos en el contexto del estallido social, la militarización del Wallmapu, etc.

En ese marco, resulta por lo menos disociado el que ciertos analistas no se hagan cargo de que esa demanda de obediencia y apego a la norma por parte de las nuevas generaciones no es automática. ¿Qué otra cosa se podía esperar? Más aún cuando esa demanda de obediencia se hace desde un locus fracturado y una herencia trágica repleta de ambivalencias e inconsistencias vivenciales, cuyo efecto más pernicioso — en las nuevas generaciones- es un repliegue en el presente y en la confortabilidad (o infierno) de "mi propia burbuja", incrementando la descomposición del lazo social y la sensación de incertidumbre sobre un futuro posible.

En ese sentido, aclarar que la generación más joven (o cualquiera de sus facciones) actúa como barómetro de las nuevas tendencias culturales, políticas, económicas, etc. donde la aceleración de las tendencias sociales se deja ver más penetrante en estos componentes de la población, debido a que poseen una inédita capacidad para asimilar, procesar e integrar transversalmente la información y los códigos sociales desanclados que hoy circulan por todo el planeta (Margulis, 2003). Rossana Reguillo (2000) habla de "metabolismo acelerado"; una condición mediante la cual los y las jóvenes actuales introyectan y reproducen de modo más intenso los patrones discriminatorios de la cultura dominante, como el sexismo, el hedonismo, la auto-referencialidad, la descalificación del otro, etc.

Por otra parte, también se pueden observar en las nuevas generaciones 
procesos de agenciamiento importantes, donde se re-elaboraban activamente e impugnan con la misma fuerza esos patrones de la cultura hegemónica, mediante complejas operaciones cognitivas, socio-emocionales, estéticas y simbólicas, de colaboración y denegación de la política oficial (Reguillo, 2000).

Una parte importante de nuestro trabajo, desde fines de los años 90 (Ganter y Zarzuri, 1999; Zarzuri y Ganter, 2002), viene dando cuenta que estamos frente a una incesante y subterránea marea que erosiona las instituciones sociales de la tardo-modernidad (familia, escuela, iglesias, Estado, trabajo, política, tribunales de justicia, Carabineros, Ejercito, modos convencionales de producción y transmisión del conocimiento, etc.), y que hoy se presenta en la forma de estallido social, asociado con una importante crisis de autoridad, esto es, de hegemonía; con toda una "multitud" de desertores que se vienen acumulando y multiplicando por décadas, particularmente en el caso chileno (por las razones que están a la vista de todas/os), donde tiende a prevalecer la hipótesis sobre un nuevo malestar social en la juventud actual, que plantea el predominio de una corriente cultural que hace que los adultos se evaporen o diluyan. Lo que implica un poderoso cambio de ciclo político.

Esto significa una ruptura en la transmisión de sentidos compartidos, donde se observa a la generación adulta profundamente cuestionada, desautorizada y desprovista para encarnar un testimonio que transmitir a las nuevas generaciones (una invitación a participar protagónicamente), o por lo menos, se observa con signos importantes de fatiga y renuncia parcial a dicho mandato, dado que se ha llegado a un punto cero de su cultura. Esto es, se desfondó su autoridad y su proyecto de futuro. Sus ideologías y proyectos políticos parecen agotados, su autoridad está impugnada, su proyecto de sociedad viene perdiendo legitimidad y capacidad para invitar y convocar a las nuevas generaciones. La evaporación del adulto aquí implica la evaporación del peso simbólico de la diferencia generacional, de encarnar el límite, esto es, la diferencia entre padres/madres e hijos/as. La generación actual quedaría, entonces, arrojada a una suerte de vacío, una generación sin referentes más que ellos mismos. Así, pasaríamos del conflicto entre generaciones (años 60) 
a la confusión entre generaciones (siglo XXI: el sueño adulto de la eterna juventud). En este escenario, será difícil para las nuevas generaciones sentirse re-conocidas y validadas por una autoridad o referente que otorgue certidumbres. Lo que se traduce en una sensación de abandono y deriva de las nuevas generaciones, obligadas a inventar su propio camino. Lo que implica desafíos, pero también riesgos importantes para la convivencia y la colaboración intergeneracional (Recalcati, 2014).

De ahí que, más allá de lo que algunos columnistas han pontificado como beatería juvenil (metiendo todo en un mismo "saco": anarquismo, barras bravas, narcotráfico, etc.), sin hacerse cargo de su propio sesgo academicista y cautivo de una única, excluyente y universal forma de racionalidad, nosotros venimos debatiendo - modestamente- desde fines de los años 90' con el binomio que concibe la condición juvenil únicamente como reserva moral del futuro (polo redentor y mesiánico), o bien, como un problema social y moral a gestionar (polo epidemiológico, o sea como una epidemia que hay que evitar que se siga expandiendo). Bajo este binomio explicativo, la condición juvenil y las nuevas generaciones (tan diversas como desiguales), quedan suspendidas en un futuro que nunca se hace presente, o bien, aparecen como un problema de orden público a resolver, desechando y descalificando la posibilidad de considerarlas como agentes activos y coprotagónicos (con luces y sombras), en la construcción creativa de historicidad y de una sociedad entendida como proyecto colectivo, plural, dinámico y colaborativo.

A pesar de lo anterior, observamos el rol activo que vienen jugando un gran número de jóvenes en el actual escenario, en tanto agentes públicos detonantes y difusores de demandas que exceden sus propios intereses particulares, poniendo en la agenda temas que las generaciones que los anteceden no pudieron empujar ni alcanzar: prensiones dignas, garantías y coberturas de salud, nueva constitución política, educación no sexista, reconocimiento al pueblo Mapuche, protección de los recursos y bienes comunes, etc.

Los cambios culturales que ha incorporado la sociedad chilena imponen un nuevo escenario de oportunidades y amenazas en cuyo marco 
debe vivirse la juventud actual (PNUD, 2003). Como ya se planteó al inicio, los efectos de este cambio cultural tienen un impacto especial entre los y las jóvenes, dado que son las nuevas generaciones quienes mejor aprovecharán las oportunidades que trae el cambio cultural, aunque también reciben con mayor fuerza las ambivalencias y avatares de ese proceso, las dinámicas de exclusión, desafuero, estigmatización, desigualdad, endeudamiento, precarización, desconfianza e incertidumbre que caracterizan el escenario chileno actual.

\section{CONSIDERACIONES FINALES}

a) Apuntes sobre el Factor Generacional:

Reconociendo que el fenómeno del denominado estallido social es un fenómeno inédito en la historia de Chile, dado su carácter masivo, explosivo, nacional, sostenido en el tiempo y transversal en sus modos de participación, involucramiento, demandas y composición social; estamos en condiciones de afirmar que en rigor obedece a múltiples causas y otros tantos efectos desencadenantes, por tanto no puede explicarse exclusivamente por una situación extendida de malestar colectivo, ni tampoco por un aumento exponencial de las expectativas de integración por parte de la ciudadanía y que el modelo no pudo absorber. Dicho eso, reconozcamos entonces en su propio mérito lo que aquí hemos denominado el factor generacional y sus vasos comunicantes con el 18-O.

Planteamos que lo que constituye a una generación no se asocia precisamente con el compartir fecha de nacimiento, sino con el compartir esa parte del proceso histórico, de la cual los jóvenes contemporáneos son testigos vivenciales. Entre los elementos básicos que incluye ese compartir se encuentra: (i) la presencia de acontecimientos que rompen la continuidad histórica y marcan un antes y un después en la vida colectiva (en nuestro caso los ciclos de protestas de los años 2006, 2011, 2018, 2019); y (ii) el hecho de que estos acontecimientos sean experimentados por individuos que se encuentran en una situación formativa desde el punto de vista de su socialización e identidad (jóvenes), por lo cual los esquemas utilizados para 
interpretar la realidad aún son flexibles y porosos (Leccardi y Feixa, 2011).

En ese sentido, Mannheim (1993) plantea que el primer requisito para que puedan aparecer formas compartidas de ver, sentir y experimentar la vida, común a un conjunto de individuos, es que co-habiten una misma "situación generacional", que es el punto donde converge el tiempo histórico y las condiciones biográfico-sociales de existencia.

Lo anterior permite la configuración potencial de "unidades generacionales", a veces en franca disputa entre ellas, y por tanto la elaboración de nuevas visiones de mundo (Mannheim, 1993), es decir, gérmenes de una nueva "subjetividad generacional", una nueva forma de pensar, sentir y vivenciar la vida, que en algunos casos específicos, como los que aquí hemos tematizado, tienen el potencial de convertirse en "espíritu de época", una "sensibilidad vital" particular e influyente en el devenir histórico y cultural de una sociedad (Álvarez, 2018; Ghiardo, 2004; Leccardi y Feixa, 2011; Mannheim,1993; Muñoz, 2011; Ortega y Gasset, 1955).

A modo de balance preliminar, y buscando hacer conexiones generacionales y epocales, que nos permitan sugerir y evocar pistas para comprender provisoriamente este otoño civilizatorio (Reguillo, 2017), parece interesante el ejercicio de contrastar y homologar el actual cambio de siglo y de ciclo político, con lo que estaba ocurriendo hace prácticamente 100 años atrás en Chile, esto es, iniciado el siglo XX. Si nos remontamos a ese momento (Salazar, 2002), allí observamos la configuración de una generación (1920), y de un movimiento juvenil, preferentemente de estudiantes de clases media urbana, que estuvo marcado por: (i) el surgimiento de la denominada "cuestión social" y la aparición en 1906 de una epidemia crítica de viruela, en tanto hitos detonantes; (ii) un profundo malestar colectivo con un régimen político de tipo parlamentario y oligárquico, con importantes niveles de desigualdad y abuso; (iii) el desarrollo de sentimientos generacionales y aspiraciones de cambio que confrontaron el autoritarismo de las elites, el régimen oligárquico, la política de partidos; (iv) el despliegue de movilizaciones masivas, muchas de estas en alianza con sectores obreros, como las marchas por el hambre; otras veces combinaron la acción directa callejera con repertorios de acción colectiva de 
tipo expresivos y carnavalescos; (v) el desarrollo de activismos plurales de tipo socio-culturales y de carácter autónomo, más que centrados en lo políticoideológico; (vi) el desarrollo de una nueva coyuntura constitucional; entre otros. Por ahora, con humildad y modestia, más que responder, únicamente nos cabe plantear preguntas: ¿cómo le fue a esa generación y movimiento? ¿cuáles fueron sus agendas, rendimientos, conquistas y derrotas? ¿a qué situaciones nos precipitó el empuje de esa generación? ¿cuáles son sus herencias, heridas y aprendizajes? ¿qué ocurrió posteriormente a nivel global, en los años 30, con la crisis económica y el cuestionamiento a la democracia liberal? ¿qué lecciones y potenciales retornos podemos observar en el aquí y el ahora de vuelta al año 2020 ?

Así, desde una perspectiva histórica y relacional, el factor generacional, sin asumirlo de modo determinista, constituye un factor relevante al momento de pensar no solo los cambios y recambios al interior de un tablero político determinado, o bien, los cambios al interior de un régimen político hegemónico, sino que muchas veces ha implicado rupturas gravitantes, la vuelta completa del tablero, un cambio profundo de régimen y sus bases de sustentación. Cuestión que hemos podido observar progresivamente para la coyuntura del 18-O, por ejemplo, con la demanda de una nueva constitución política vía asamblea constituyente.

Lo anterior no viene sucediendo de la noche a la mañana, sino que ha implicado un proceso largo de disputas, alianzas y aprendizajes intergeneracionales a partir de diferentes "situaciones generacionales", la mayoría de las veces con altos costos personales y duros fracasos colectivos, donde las soluciones a las demandas - hasta ahora - habían sido resueltas a través de comisiones con control de expertos, medidas correctivas y sectorializadas, como en el caso de la "revuelta de los pingüinos" el año 2006 y la comisión presidida por Carlos Peña. El correlato de aquella "situación generacional" inevitablemente no fue solo el aumento de la sensación de derrota y frustración para el caso de esa "unidad generacional" en particular, sino también el inevitable aumento de la presión sobre el propio sistema político, su legitimidad y sus actores, con la consecuente acumulación subterránea de 
fuerzas evidentemente explosivas.

No obstante, esas alianzas y aprendizajes intergeneracionales también han estado repletos de sueños y deseos cargados de otros mundos posibles, que muchos denostaron, se negaron a ver o simplemente se mofaron, sobre todo cuando se nos repetía cotidianamente el mantra de que no había alternativas por fuera del orden neoliberal. En palabras de N. Lechner:

Para llevar a cabo reformas políticas necesitamos realizar, ante todo, una reforma de la política. Ello implica mirar más allá de la política institucional (...) A menudo se analizan la dinámica institucional, la estrategia de los actores y los condicionamientos económicos sin considerar debidamente la experiencia diaria de la gente, sus miedos y sus deseos. Las callejuelas de la vida cotidiana son frecuentemente callejones sin salida, pero a veces permiten vislumbrar la cara oculta de las grandes avenidas (1988: 18).

Lo que demuestra, a nuestro juicio, que el rol detonante y difusor que han venido jugando estas "unidades generacionales" durante este proceso no ha sido menor, dado que han contribuido a precipitar una metamorfosis en los imaginarios políticos, corriendo el límite de lo posible y poniendo en cuestión el motor de la propia subjetivación neoliberal y el estilo de vida que esta lleva implícito. ${ }^{8}$ Con ello, destacamos el rol de etas unidades generacionales que se han expresado protagónicamente en estos últimos 20 años, en tanto agentes

8 Aclaremos que cuando hablamos de una "unidad generacional" no nos referimos necesariamente a un universo homogéneo de individuos que comparten una fecha de nacimiento cercana y un espacio geográfico más o menos delimitado, sino que nos referimos al espacio donde converge la edad de los individuos con la vivencia de un mismo acontecimiento histórico/social; cuestión que potencialmente puede generar modos de pensar, sentir y actuar compartidos sobre una situación social. En este caso es muy probable que los estudiantes secundarios agrupados en Aces o Cones, constituyan parte de una misma "unidad generacional" en el contexto del estallido social, lo propio respecto de los jóvenes que han participado en la denominada primera línea durante el mismo escenario. Lo anterior implica la construcción de lazos sociales y de pertenencia, una visión compartida de mundo. De modo que, reconociendo que no toda "la" juventud se sumó a la movilización ciudadana del 18-O, vivir una misma situación generacional no necesariamente implica ser parte de una misma unidad generacional, de hecho el estallido social terminó por incubar al menos dos unidades generacionales más o menos distinguibles y opuestas, los que se movilizan en el sector de la llamada Plaza de la Dignidad y los que se movilizaron en el sector de la Escuela Militar en Santiago de Chile, estos últimos con un claro rechazo a la agenda de transformaciones sociopolíticas. 
portadores de una otra cultura política, que irrumpe para señalarnos lo que hay que descartar, soltar, desaprender, para poner todo nuestro esfuerzo en conquistar - colaborativa y participativamente - lo que aún tenemos como deuda social y política pendiente en nuestra urgente agenda de país.

De ahí que el factor y la condición generacional, junto al género, pueda ser pensado como uno de los motores de cambio social más gravitantes y poderosos, como en su tiempo lo pudo ser la clase social. Lo que no significa, y en esto somos muy enfáticos, que lo generacional constituye un fin en sí mismo, un atributo intrínseco adscrito a cierto grupo de edades específico (la reserva moral del provenir), ${ }^{9}$ sino más bien una cierta condición de alguna forma latente, una posición de sujeto que potencialmente podría configurarse en factor detonante de procesos de transformación social, en ensamble - por cierto - con otros factores y condiciones sociales que permitan producir nuevas tramas de sentido compartidas entre múltiples posiciones de sujeto/as.

b) Sobre la (re)politización de la política y los nuevos activismos convergentes

"Son tantas weas...que no sé qué poner" (Graffiti difundido en los muros de las calles $y$ en las pancartas de lxs manifestantes durante la revuelta social del 18-O)

Sobre el fenómeno de la repolitización de la política en particular, que muchos consideran como un fenómeno reciente (PNUD, 2015), ya veníamos sosteniendo desde los primeros años del siglo XXI que:

9 Parafraseando a Mannheim (1993): nada más impertinente en este marco que suponer analíticamente que la juventud sea en sí misma progresista y la vejez en sí misma conservadora. 


\begin{abstract}
Uno de los rasgos más significativos de este cambio cultural, se juega en el giro político que hacen los jóvenes en el mundo contemporáneo, en el reemplazo de modelos políticos representativos decimonónicos por modelos de autorepresentación colectivo-juvenil, o bien, de modelos partitocráticos de gestión política, por modelos de democracia directa desde la base. Esto también puede ser leído como un desplazamiento del paradigma militante que caracterizó a las máquinas políticas centralizadas en burocracias administrativas, hacia modelos ciudadanos de raigambre comunal, configurados por redes locales descentralizadas y autogestionadas, no jerarquizadas estructuralmente, con participación activa en la toma de decisiones, donde se privilegia la acción directa sobre objetivos concretos e inmediatos, y cuyo trabajo se orienta principalmente a la re-politización de la vida cotidiana" (Ganter, 2004: 256).
\end{abstract}

Más recientemente, observamos —empíricamente - un aumento importante y sostenido de la movilización colectiva en Chile, particularmente desde inicios del Siglo XXI (PNUD, 2012/2015), y protagonizada por jóvenes pertenecientes a diversas unidades generacionales vinculadas con las distintas mareas del movimiento estudiantil: el llamado mochilazo (Aces) el año 2001, la revuelta pingüina por la educación pública el año 2006, el No + Lucro en la educación del año 2011, el mayo feminista que partió en contextos estudiantiles universitarios el año 2018, y el rol detonante del 18-O con las evasiones masivas de estudiantes secundarios en el Metro de Santiago, luego el sabotaje/boicot a la Prueba de Selección Universitaria (PSU) en enero del año 2020, y el papel que han desplegado estas "unidades generacionales" en la sostenibilidad de una agenda de cambios estructurales y de la propia movilización callejera post-estallido social, particularmente a través de lo que se conoce como "primera línea".

Esta poderosa inyección de politicidad generacional hacia la sociedad chilena, no se observó de modo explícito durante toda la década de los 90 y la transición a la democracia en Chile, aún cuando estamos conscientes que esas dinámicas de repolitización responden de modo más fuerte al quehacer de lo que se conoce como minorías activas dentro del segmento juvenil, esto es, a "unidades generacionales" específicas asociadas con el protagonismo desplegado al interior de cada ciclo de protesta $(2001,2006,2011,2018,2019) .{ }^{10}$

10 En perspectiva intergeneracional, reconocemos de modo preliminar 2 herencias cultuales 
Sin embargo, si lo observamos de manera más amplia que la referencia a la "unidad generacional" específica, la evidencia sostiene que el segmento entre 18 y 30 años figura como el que mayoritariamente participa en protestas y manifestaciones, con el 46\% (Somma, 2015). Evidenciándose que las nuevas generaciones tienden a simpatizar más fuertemente con la agenda de cambio impulsada por movimientos sociales, mostrando mayor interés por participar - sin mediación alguna - en actividades que se divorcian de la política institucional y de las modalidades tradicionales de participación, aspirando con ello a cambios más radicales y estructurales que las generaciones que los anteceden (PNUD, 2015).

Lo anterior obedece, a nuestro juicio, a múltiples causas, dentro de las cuales podemos destacar la irrupción de nuevas formas de aprendizaje/socialización política que impugnan la política oficial, y que vienen sedimentándose de modo progresivo en las nuevas generaciones, preferentemente desde inicios del siglo XXI en Chile. Estas formas de aprendizaje/socialización política se asocian con el involucramiento masivo por parte de jóvenes en eventos contenciosos como: marchas, protestas, "tomas" sistemáticas de liceos y universidades, asambleas de diversa índole, cabildos auto-convocados, producción de talleres y frentes cultuales,

y generacionales, que se descuelgan de las maquinarias típicamente militantes y partidistas, sin las cuales no hubiera sido posible observar en Chile las mareas generacionales y el carácter de los movimientos estudiantiles de inicios del siglo XXI. Nos referimos, primero, a la "Corriente Cultural Latente" germinada entre los años 1976-1986, donde interaccionan 3 procesos juveniles relevantes: la Agrupación Cultural Universitaria; la Acción Cultural Juvenil al interior de las parroquias en las poblaciones; y el polo de cultura Alternativa o Under de la primera parte de los años 80', en principio más dispersos, pero luego con epicentro en garaje Matucana y galpón Trolley; sin los cuales resulta impensable el movimiento popular y la épica de las protestas masivas contra la dictadura entre los años 1983 y 1986; sumando fuerzas opositoras al dictador en el plebiscito del año 1988. En segundo lugar, y conectada con la corriente anterior, identificamos a la "Corriente Cultural Latente" germinada a partir del "descontento" con el tipo de transición política operado, entre los años 1989 y 2001, donde interaccionan al menos 3 procesos juveniles relevantes: la emergencia de colectivos universitarios, como la Surda; la neo-tribalización de estilos juveniles interclasistas, con la subsecuente construcción de redes territoriales; y el despliegue del polo bohemio-festivo a partir de las fiestas Spandex, con su cuestionamiento a los códigos heteronormativos, y el "carrete juvenil" como forma de reconstrucción por abajo. A nuestro juicio, las corrientes cultuales y generacionales, tan plurales como impugnatorias, que se manifestaron de modo latente en los 2 períodos históricos señalados, habitan de modo profundo en el ADN de las mareas generacionales observadas para los ciclos de protesta de los años 2006, 2011, 2018 y 2019 en Chile. Sus modos de participar y organizarse, sus repertorios de acción colectiva, sus prácticas culturales autónomas y expresivas, son signos importantes de lo anterior. 
participación en foros y redes sociales ciber-activas, generación de espacios de interacción feminista de carácter separatista, creación de repertorios performativos de acción e interacción colectiva en el espacio público, con alto impacto simbólico y socio-emocional, entre otras. ${ }^{11}$

Dicha corriente social, ha contribuido a cuestionar los límites actuales de lo político en la sociedad chilena, precipitando una agenda extensa y heterogénea de politización, asociada con asuntos que antes no tenían necesariamente un carácter político (PNUD, 2015); como por ejemplo: el rol público en la educación, la impugnación del lucro en la educación, el cuestionamiento del sexismo en la educación, la denuncia del abuso y el acoso sexual en las universidades, la despenalización del aborto, la legalización de la marihuana, la crisis climática, las zonas de sacrificio, la protección y el cuidado de los bienes comunes, la soberanía alimentaria, la precarización de la vida y el sobre-endeudamiento de las familias, las luchas contra el especismo, los derechos de las comunidades LGBT, el cuerpo y los afectos como territorio político, la denuncia de la brutalidad policial y las violaciones a los derechos humanos en contextos de movilización ciudadana, las luchas por la dignidad, el reconocimiento y el respeto. Todas, dimensiones que ya habíamos puesto en valor desde los primeros textos que escribimos a fines de los años 90.

Este nuevo ciclo de politización, impugnaciones y acumulación de malestares colectivos al que hacemos referencia, llegó a su clímax durante el reciente ciclo de protestas masivas del 2018-2019, poniendo en jaque al propio sistema político y sus bases de sustentación, pero sobre todo prefigurando una subjetividad política con un importante componente generacional (aunque no excluyente); y que se expresaría en tres niveles básicos y relacionales de la "experiencia" compartida (Pleyers, 2018): (a) una visión alternativa de mundo, que implica nuevas concepciones de lo público, lo político y la

11 Muy importante resulta aquí, insistir, que no se trata de pensar reduccionistamente a las juventudes como sujetos redentores un escenario de crisis civilizatoria; sino de asumir un enfoque interpretativo donde lo generacional, y más precisamente lo intergeneracional, pueden ofrecernos pistas significativas en el marco de diagnósticos y propuestas más relacionales y multidimensionales para comprender — gramscianamente - una época donde lo viejo no termina de morir y lo nuevo no termina de nacer. 
democracia; (b) una forma alternativa de vivenciar-estructurar la organización y la participación ciudadana, que implica una fuerte despartidización de la política en beneficio de otras orgánicas menos jerárquicas y más rizomáticas; (c) la escenificación innovadora de repertorios de acción colectiva de fuerte contenido simbólico y emocional, que implican una potente interacción ritual entre el arte, el cuerpo, lo festivo y lo digital como herramientas al servicio de lo que aquí llamamos activismos de tipo convergentes, donde se sincronizan múltiples causas y agendas ciudadanas heterogéneas al interior de una subjetividad colectiva o singular.

Sobre el mismo plano, poner en valor que una de las novedades de este nuevo ciclo de re-politización y de la propia revuelta social de octubre del año 2019, no estuvo únicamente asociado con el despliegue de activismos sincrónicos y convergentes, incluido el de la calle y el digital, sino que las propias demandas y las agendas de distintas generaciones también tendieron a sincronizarse, lo que marca una diferencia importante con otros ciclos de protesta, que estarían más centrados en una "unidad generacional", mientras que lo ocurrido en el 18-O respondería más bien a una expresión de complicidad y sincronía entre generaciones diversas (abuelos/as y nietos/as, etc.), pero con repudios, demandas y agendas convergentes.

Por último, en momentos de (auto)confinamiento, donde la agenda de la revuelta del 18-O en Chile parece coincidir con la agenda de la pandemia del Covid-19, sobre todo en materia de desigualdad, precarización de la vida, desfondamiento del poder político, ausencias de coberturas sociales y sanitarias sostenibles, etc. el horizonte y la potencial salida a esta fractura social y política, esto es, una convención o asamblea constituyente, aparece como un espejismo que se desdibuja en la medida que avanza el invierno, el frío, el hambre de ciertos sectores de la población y la presión sobre el sistema sanitario; aun cuando la potencia colectivo-creativa y la memoria social encarnada y grabada a fuego en amplios y heterogéneos sectores de la población, respecto de lo que fue la revuelta social como hito biográfico e intersubjetivo, no se borrará tan fácilmente, quedando pendientes para los siguientes años sus múltiples pliegues y derroteros, sobre todo en lo que 
respecta a la puesta en juego de nuevos actores sociales y generacionales, con sus respectivas agendas sociales y políticas.

\section{REFERENCIAS}

Álvarez, C. (2018). "La perspectiva generacional en los estudios de juventud: enfoques, diálogos y desafíos". Revista Última Década, 26(50), 40-60. https://bit.ly/3hT6EUY

Andonie, M. (2020). La “primera línea”: ¿individualistas o filántropos. E1 Mostrador. Consultado el 24 de febrero de 2020. https://bit.ly/2PhIwiM

Claude, M. (2020) Retrato de un clan de la Primera Línea. Ciper. Consultado el 24 de febrero de 2020. https://bit.ly/2DsvZ9k

Fernández Droguett, R. (2020). La Primera Línea y todas las Líneas del levantamiento social en Plaza de la Dignidad. DiarioUchile. Consultado el 20 de marzo de 2020. https://bit.ly/3hT6OM4

Ganter, R. (2004). “Micropolíticas de lo Juvenil y Saberes Inconclusos”. En N. Richard (Ed.), Revisar el pasado, criticar el presente, imaginar el futuro. Santiago, Chile: Ediciones Universidad ARCIS.

Ganter, R. y Vergara, C. (2015). “Fisonomías del Mal-Estar Juvenil: ubicuidad y radicalidad generacional”. En O. Basulto. Diálogos sobre juventud en lberoamérica. Editorial Universidad de Santiago de Compostela.

Ganter, R., Vergara, C. y Fuica, I. (2017). “Caleidoscópolis: signos de cambio en los repertorios de protesta callejera en Concepción". Revista Universum, 32 (2), 81-105.

Ganter, R. y Zarzuri, R. (1999). Tribus urbanas: por el devenir cultural de nuevas sociabilidades juveniles. Perspectivas, (8), 5-19.

(2005). "Metamorfosis de lo político - cultural y colectivos urbano juveniles emergentes". En M. Sepúlveda (comp.) Nuevas Geografías Juveniles. Ediciones Universidad Diego Portales.

Ghiardo, F. (2004). “Generaciones y Juventud: una Relectura desde Manheim y Ortega y Gasset”. Revista Última Década, 12 (20), 11-46. 
González, Y. (2010). "Sumar y no ser sumados: culturas juveniles revolucionarias. Mayo de 1968 y diversificación identitaria en Chile”. Revista ALPHA, (30), 111-128.

González, Y. y Feixa, C. (2013) La construcción histórica de la Juventud en América Latina. Bohemios, Rockanroleros \& Revolucionarios. Editorial Cuarto Propio.

Güel, P. (2019). "El estallido social de Chile: Piezas para un rompecabezas". Revista Mensaje (685).

Leccardi, C.y Feixa, C. (2011). "El concepto de generación en las teorías sobre juventud". Revista Última Década (34), 11-32.

Lechner, N. (1988). Los Patios Interiores de la Democracia. Subjetividad y Política; Editorial Flacso.

Mannheim, K. (1993). "El problema de las generaciones”. Revista Española de Investigaciones Sociológicas, (62) 193-242.

Margulis, M. (2003). Juventud, Cultura, Sexualidad: la dimensión cultural en la afectividad y la sexualidad de los jóvenes de Buenos Aires. Editorial Biblos.

Mead, M. (1977). Cultura y Compromiso. Editorial Gedisa.

Medel, R. y Somma, N. (2016). “¿Marchas, ocupaciones o barricadas? Explorando los determinantes de las tácticas de la protesta en Chile". Revista Política y Gobierno, 23 (1) 163-199.

Muñoz, G. (2019). "Primera línea, los héroes anónimos de la resistencia en Chile". Desinformémonos. Consultado el 21 de marzo de 2020. https:// bit.ly/3i0Yeee

Muñoz, V. (2011). "Juventud y Política en Chile. Hacia un enfoque generacional". Revista Última Década, (35), 113-141.

Organización de las Naciones Unidas (2019) Informe sobre la misión a Chile 30 de octubre - 22 de noviembre. Informe Derechos Humanos - Oficina de Alto Comisionado.

Ortiz, I, Burke, S, Berrada, M y Cortes, H. (2013). World Protests 2006-2013. Initiative for Policy Dialogue and Friedrich-Ebert-Stiftung New York. 
Ortega y Gasset, J. (1955). El tema de nuestro tiempo. Espasa-Calpe. (Original publicado en 1923).

Pleyers, G. (2018). Movimientos sociales del Siglo xxi. Perspectivas y herramientas analíticas. Editorial Clacso.

Programa de las Naciones Unidas para el Desarrollo (1998).Desarrollo humano en Chile: las paradojas de la modernización. Informe de desarrollo humano en Chile.

(2003). Transformaciones culturales e identidad juvenil en Chile. Temas de desarrollo humano sustentable.

(2012). "Bienestar subjetivo: el desafío de repensar el desarrollo". Informe desarrollo humano en Chile.

(2015). "Los Tiempos de la politicidad". Informe desarrollo humano en Chile.

Recalcati, M. (2014). El complejo de Telémaco. Padres e hijos tras el ocaso del progenitor, Editorial Anagrama.

Reguillo, R. (2000). Emergencia de Culturas Juveniles. Estrategias del Desencanto. Norma Editorial.

(2017). Paisajes insurrectos. Jóvenes, redes y revueltas en el otoño civilizatorio. NED ediciones.

Salazar, G. y Pinto, J. (2002 vol. 5). Historia Contemporánea de Chile, Niñez y Juventud. Editorial LOM.

Somma, N. (2015, octubre). Protestas y conflictos en el Chile contemporáneo: quince tesis para la discusión. ResearchGate. Consultado el 30 de marzo 2018. 10.13140/RG.2.1.3820.6161

Santibáñez, P. y Ganter, R. (2016). "Representaciones sociales de lo político: Convergencias y divergencias del relato generacional en el gran Concepción". Revista Última Década, 24 (44), 39-70.

Tarrow, S. (1997). El Poder en Movimiento: Los Movimientos Sociales, la Acción Colectiva y la Política. Alianza Editorial.

Valenzuela, J.M. (coord.) (2013). Juvenicidio. Ayotzinapa y las vidas precarias en América Latina y España. Editorial NED. 
Zarzuri, R. y Ganter, R. (2002). Culturas juveniles, narrativas minoritarias y estéticas del descontento. Editorial UCSH.

(2016). "Giro cultural y estudios de juventud en el Chile contemporáneo: crisis de hegemonía, mediaciones y desafíos de una propuesta". Revista Última Década, 26 (50), 61-88.

Zarzuri, R. (s. f.) "El malestar en los jóvenes chilenos y las movilizaciones estudiantiles en el Siglo XXI". En G. De la Fuente y D. Mlynarz (Ed. y Comp.). El pueblo unido...el malestar en movimiento [manuscrito presentado para publicación]. Editorial CATALONIA.

Zarzuri, R. y Henríquez, K. (2020). Primera línea: accionar desde el cuerpo, encuentros, persistencias y contraviolencias en el espacio público [manuscrito presentado para publicación]. Editorial LOM. 